\title{
Scopes and aims in anaesthesia and critical care nursing
}

Ina Welk, RN, CRNA, CCRN, Project Manager, AK Altona, Paul-Ehrlich-Str. 1, 22763 Hamburg, Germany

Starstr. 33, 22305 Hamburg, Germany. e-mail: ina.welk@ak-altona.lbk-hh.de

\section{INTRODUCTION}

As nursing becomes increasingly professional, it is necessary to pursue its development and to define new goals in the field of specialist nursing, specifically in anaesthesia and critical care nursing.

If specialist nursing is considered to be a field of great responibility and to have equal status with other professions in the health care sector, it is necessary to question the current static balance between the medical and nursing professions. It is important to pursue an integrated co-operation between both professions in order to define their common goals.

The complicated field of anaesthesiology and intensive care medicine is no longer conceivable without the competent, collaborative co-operation of specialised and trained nursing staff with the medical profession.

\section{HISTORICAL BACKGROUND}

The current problems faced by the nursing profession in terms of building up an independent identity and professional structure, and in defining professional nursing standards cannot be understood without viewing the historical development of nursing.

The origins of nursing in the 19th century began with middleclass, unmarried women, who began to look towards nursing as a sensible occupation. Nursing provided well-respected work within the social framework of the period. However, the nurses received no pay and were constantly supervised by doctors. The work of the nurses depended entirely upon the doctor's diagnosis.

The professional standards of anaesthesia and intensive nursing care also have an historical background:

- After the First World War, ether drips were administered by nursing staff.

- The profession of anaesthetist was created during the 1960s, and required well-trained nursing assistants.

- The first courses for anaesthesia and intensive care nursing were set up during the 1970s without creating an independent profession.

- There has been a greater focus on anaesthesia and intensive care nursing since the 1980s, resulting in the definition of new purposes and fields of work.

\section{DIFFERENCES IN TRAINING BETWEEN COUNTRIES}

The International Federation of Nurse Anaesthetists (IFNA) began the first collection of information and analysis of training structures and contents in 1989. The information collected was descriptive, concerning the educational process for instructing nurses in anaesthesiology, within each country throughout the world.

An international study on training contents and duration has shown that individual countries have different structures and statuory requirements for nurse trainining in anaesthesiology. These problems were first presented in 1994 at the first educational forum at the 4th World Congress for Nurse Anaesthetists in Paris, France.

For example, Germany has a combined programme of nurse anaesthesia and intensive care. Applicants must be registered nurses, who have already received a three-year diploma course in nursing. The educational programme for nurse anaesthesia and intensive care covers many hours of theory and practice, with a theoretical, practical and written examination taken after two years of study. Qualified nurses are licensed and certified as nurse anaesthetists.

\section{TEAMWORK AND PROFESSIONAL DEVELOPMENT}

In these specialist areas in particular, it is necessary for doctors and nurses to work together closely. The aim is to form a therapeutic team, in which each member is a specialist. Each professional group is required to question continually the content and tasks of their profession and to reorganise work processes, breaking open traditional roles as required. Professionalism is a never-ending and dynamic process.

Some countries, such as Switzerland and the Netherlands, consider that it is sufficient to have apparently cost-efficient 'surrogate professions', such as doctor's assistants and technical surgical assistants, rather than specialised nurses in anaesthesiology. It therefore becomes necessary for other countries, such as the UK, to define clearly why their nursing staff cannot be replaced. Instead, these countries believe it is necessary to extend the areas of nursing application, with qualifications and multiprofessionalism having primary importance. It is also important to note that multiprofessional should not mean multifunctional!

\section{POSSIBLE AREAS OF APPLICATION}

The possible areas of nursing care that can benefit from this process of continual professional development include: 
Further training (teaching)

- Scientific research (study nurse)

Emergency services

- Ambulatory pain treatment

- Medical engineering

- Controlling: (costs, benefits and effectiveness)

- Recovery room

- Intermediate care

- Perioperative treatment unit

- ICU

1 Hygiene

- Materials

- Business studies

- Operational co-ordination

- Management.

The advantages of approaching nursing care in this way include:

- Breaking open of traditional structures

- Additional motivation (by extending the range of offers)

- Cost reduction through targeted personnel development (individual career planning)

- Development of standards

- Quality assurance

Competition

Promotion of young nurses

- Reduction in fluctuation (through identification, flexibility, job-rotation)
- Social-friendly aspects (variable activities of longer-serving staff)

- Strategic aspects to combat' burn-out syndrome'

- Increased possibility of adequate remuneration

- Personnel resource pool (need-orientated, pan-specialist work planning).

The aim of nursing professional development is to:

- Create multiprofessionalism in a patient-orientated, therapeutic team

- Exchange information

- Work together at an international level on content, theoretical and practical guidelines to improve the training of anaesthesia and intensive nurses.

\section{CONCLUSION}

It is very important to discuss innovative and future-orientated strategies in our health care systems and to enable active participation in redefining our self-confidence, as critical care nurses, as experts in nursing anaesthesia and intensive care.

\section{FURTHER READING}

Buck RA, Vitt KD. Nursing in front of new tasks. Practice manual for the working place hospital. Stuttgart: Thieme Verlag.

Schulte am Esch J, Goerig M. (1997). The History of Anaesthesia. Proceedings of the Fourth International Symposium on the History of Anaesthesia. Hamburg: Dräger Verlag.

INTERNET GONNEGTIONS

\section{ON THE WEB}

The recent newsletter (No. 15) of the European Society of Paediatric and Neonatal Intensive Care (ESPNIC) carried an article about electronic networking reporting the findings of Lutz Bindl, who had sent out a questionnaire to 277 ESPNIC members. One of the topics of the questionnaire was about the availability of internet access. The results showed that $76 \%$ of the responders had excellent internet access and that $73 \%$ used the internet daily.

Unfortunately, the participants of this study were doctors. What would be the results among intensive care unit (ICU) nurses? When I look at some professional web sites with an interactive discussion forum, I begin to believe that nurses do not use, or are not able to use, these resources. Or perhaps they play games on the computer during a night shift? Sure you do ... I must confess that we do on our unit.

So, the next challenging question is: where do you get further information regarding a patient with a specific problem? Do you just do 'something' without consulting other nursing experts? Can that be considered to be professional nursing?

Well, being a professional nurse, I have to tell you that collaborating with colleagues via an internet discussion forum (even from other countries) can help you solve problems in your daily practice.

Once you have found a relevant professional chat forum on the internet, bookmark this site on your desktop, so that you are only one click away from your colleagues of another ICU in Europe or even the World. Give it a try, and if you find a web site that you think might interest our readers, please let me know at jos.latour@planet.nl

\section{www.efccna.org}

Although you probably know this web site, I would like to draw your attention to the European Federation of Critical Care Nursing Associations. There is an on-line discussion forum on this web site. It has not been used very extensively, but I am happy to see that questions posted on the site are being answered by other colleagues. One of the advantages of this site is the ability to search by a keyword for a particular discussion group. For example, type CPR (cardiopulmonary resuscitation) in the search box and you will be directed to the discussion of some colleagues about a resuscitation topic.

Do not stick to the chat box of this web site. If you go back to the home page and click on the box 'members', you can jump to one of the 19 EfCCNa members' web sites, all in their own language. I am sure your language will be there as well.

\section{www.aniarti.it}

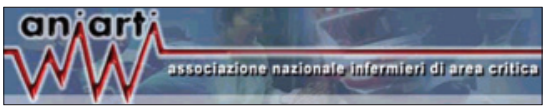
This ANIARTI web site is from our intensive care colleagues from Italy. Of course the language of this web site is Italian, but it is still worth scrolling around this site, which has lots of information. The funny thing is that this site has a chat box where you can chat online with colleagues from Italy. You can see who is online. Before you enter the chat box, however, I should point out that there is some text in Italian which I do not understand.

As a non-Italian speaking visitor to this chat box, it might be a while before a nursing colleagues replies to your question.

Jos Latour 